\title{
Commentary
}

\section{Biofuels, Bioenergy and the Bioeconomy in North and South}

Francis $X$. Johnson

\section{Stockholm Environment Institute}

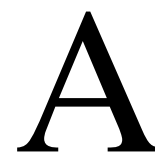

thriving bioeconomy that includes increasing reliance on biological processes and biobased products is a key element of the overall global sustainability transition. Energy can be seen as the "glue" in the bioeconomy due to the high energy requirements of modern economies and the physical interrelationships between energy and non-energy products and processes. The bioeconomy will ultimately replace the fossil economy that is characterized by high reliance on non-renewable resources. At the same time, the bioeconomy will also replace the "natural economy" that is common in the developing world, where heavy reliance on subsistence farming and traditional biomass degrade the resource base with low economic returns. A sustainable bioeconomy is also fully compatible with a circular economy in that it aims for minimal waste and the optimal valorization of biomass across all its different uses. $^{1}$ Consequently, the vision for the bioeconomy and its underlying principles should be applied in the global North and South just as the Sustainable Development Goals (SDGs) were designed to be universal in nature. The approaches, applications and implementation will nevertheless need to be adapted widely across varying levels of economic development and sociocultural conditions.

Advances in industrial biotechnology, as often highlighted in this journal, are key elements in the transition to a sustainable bioeconomy. But the environmental sustainability of the underlying resource base is even more important, since we have many industrial pathways but only one earth. Furthermore, social and economic sustainability must be addressed alongside environmental sustainability. Although we expect the bioeconomy to be more equitable than the fossil economy, there is no guarantee that biological resources will not be monopolized as fossil resources have been. Policies and institutions are especially needed to promote the interests of developing and emerging economies where biomass resources are concentrated. Economic rationalization and sustainable finance are also crucial at a time when low oil prices are placing pressure on the bioeconomy. Both the industrial and agricultural sides of the bioeconomy must be developed in sync since the weakest link in the biomass chain can threaten the collapse of markets before they can develop.

Although there is broad agreement on the need for expanding the bioeconomy there is less agreement on the pathways to get there. The role of (liquid) biofuels_-and to some extent (solid) bioenergy - has attracted particular controversy. If one believes some NGOs and their media allies, their role has gone from savior to villain during just a decade or so. The potential competition for food production has been a key point of contention. ${ }^{2}$ This debate occurs mainly within the North, even though it is supposedly out of concern for the developing South. Yet some developing countries have significant surpluses of food crops that they promote for biofuels and non-food uses; otherwise the crops will simply go to waste rather than having a reasonable chance of supporting livelihoods and rural development. ${ }^{3}$ Their challenge is to look for the right balance between industrial crops and subsistence farming - as well as finding hybrid models - a challenge that relates to development pathways more generally and not so much to biofuels or energy.

The other key issue has been greenhouse gas (GHG) emissions and other impacts associated with direct and indirect land use change. ${ }^{4}$ There is no denying that most renewable energy sources - not just bioenergy-are more land-intensive than fossil fuels or nuclear power. In a historical context, the land-intensiveness of renewables is a reckoning for the intergenerational subsidy that current generations gave themselves by extracting and using up non-renewables at an accelerating pace far beyond sustainability limits. In the case of biomass, since land is fixed, increasing population and wealth naturally creates greater demands on land. Yet these additional demands also increase competition and thus efficiency, which is sorely needed in light of the low land use efficiency of many types of agriculture and livestock use. As biofuels and bioenergy become part of integrated landscapes and production systems, the multiple products and services available contribute to continuously decreasing land use change and decreasing GHG emissions. The technology learning curve for biofuels and bioenergy thus differs from other energy sources because its scope extends far beyond energy into the entire bioeconomy.

Biofuels and bioenergy must also be placed in the context of the bioeconomy and the different uses of biomass. ${ }^{5}$ The majority of biomass used globally is for animal feed, followed by food, materials and heat/power. Only slightly more than $1 \%$ of biomass is used to produce liquid biofuels. ${ }^{6}$ If our long-run goal is to use biomass more effectively and efficiently, it is clear that the extremely disproportionate attention on the impacts of biofuels has distracted from such aims. This is not at all to suggest that the sustainability of biofuels should be ignored but rather that a more balanced approach is needed if the bioeconomy is to find a sustainable future. Deforestation, land degradation and reduced biodiversity are undesirable regardless of the uses of the 
biomass that is extracted or harvested, especially if the economic returns are so low that re-investment for environmental improvements becomes impossible. A balanced approach must also include much more attention to the demand side: the insatiable appetite for meat and cars is inconsistent not only with climate targets but also with healthy, equitable and prosperous societies.

The policy context for biofuels, bioenergy and the bioeconomy has differed somewhat in key market regions or countries, of which the European Union and Brazil are notable. The EU policy context has global implications that are especially significant in developing countries due to historical trading structures and donor relations. The role of biofuels and bioenergy has become contentious and policy positions taken less than ten years ago have already been reversed. The European Commission proposes to end the use of "foodbased" biofuels and abandon the target adopted in the 2009 Renewable Energy Directive (RED) of $10 \%$ renewables in transport, in spite of the fact that the transport sector lags far behind other sectors, with only $6 \%$ renewables by the end of 2015 , due in part to regulatory uncertainty. ${ }^{7}$ The backtracking on biofuels sent a chill through developing countries that were eyeing the EU market. It has been asserted that developing countries should produce biofuels and bioenergy for their domestic markets yet it is often not possible for them to achieve economies of scale whereas an export market could potentially facilitate expansion of their domestic markets by lowering costs. For the EU itself, this approach simply delays the transition since both advanced biofuels and electric vehicle technology are expensive and will take quite long to scale up.

The Brazilian role as a pioneer in biofuel and bioeconomy policies has tended to have more relevance for developing countries than those of the EU or United States due to similarities in climate and socio-economic conditions. ${ }^{8}$ Brazilian leadership on bioenergy has also extended to international networks and assessments aimed at creating a global framework for improving sustainability. ${ }^{9}$ Brazil's success is marked not only by its integration of bioethanol in its energy system but also its multi-product approach including sugar, ethanol, electricity and other biobased products. The high land-use efficiency of sugarcane assures it a key role in the bioeconomy of tropical and sub-tropical regions. Yet only one African country-Malawi-has fully integrated biofuels into their energy system, and most struggle to reach economies of scale both in terms of biofuels and other subsectors in the bioeconomy. A key need in the African context is to create linkages between industrial biotechnology and agribusiness development, which is among the aims of the BioInnovate program that operates in a number of countries in the region. ${ }^{10}$

Another global reality of biomass and bioenergy is that more than half of all biomass used for energy is still in traditional uses for cooking, heating and lighting. Such uses of biomass impose considerable costs on health, local ecology and productivity even as they use up considerable biomass resources only to obtain low quality energy services. In a number of identified hotspots, they are also contributing significantly to GHG emissions through land use change. ${ }^{11}$ A key aim in the transition to a sustainable bioeconomy must be to replace traditional biomass uses with more efficient and effective alternatives, including modern end-use systems coupled with modern bioenergy in the form of biogas, bioethanol, or pellets. There is little point in using literally ten times as much biomass as is needed to obtain the same energy service. By phasing out traditional biomass as modern bioenergy is phased in, the land use requirements can ultimately regain balance in global terms even as they will vary in local terms.

It is difficult to generalize about the bioeconomy solutions needed around the world but a key feature is integration. Government agencies and the markets they promote have tended to approach the different uses of biomass separately, with each sector (agriculture, forestry, energy, transport) going its own way. The fragmented approach to governing the bioeconomy has thus given rise to different policies for different uses of biomass, different incentives for investment and different regulations for the landscapes from which raw materials are sourced. This fragmentation contributed to the boom-bust policies in the EU and elsewhere. In the future bioeconomy, integrated approaches will be required across different levels, sectors, landscapes and enduses. Multi-functional landscapes and multiproduct systems are needed to move towards sustainable pathways. Consequently, we look towards agro-forestry and other integrated land use systems on the agricultural side that are also connected to biorefineries and cascading biomass uses on the industrial side.

A balanced view recognizes that - just as with any significant use of resources - there are good ways and bad ways to design and deploy the systems and markets for biofuels and bioenergy. The benefits from doing biofuels well outweigh the risks of doing it badly. ${ }^{12}$ Those benefits are greatly enhanced and the risks reduced by connecting best practices and sustainable solutions for biofuels and bioenergy to those of the broader bioeconomy in both North and South.

Francis X. Johnson has been Research Fellow or Senior Research Fellow with the Stockholm Environment Institute (SEI) for nearly twenty years. He conducts policy-oriented research on biomass, bioenergy, climate and development. As of August 2017 he has returned to the SEI Stockholm centre after two years at SEIAfrica in Nairobi, Kenya. Phone: +46 73707 8524. E-mail: francis.johnson@seiinternational.org.

\section{REFERENCES}

1. Asveld L, van Est R, Stemerding D. Getting to the core of the bio-economy: A perspective on the sustainable promise of biomass. The Hague, Netherlands: Rathenau Institute, 2011:7-14.

2. Rosillo-Calle F, Johnson FX. Food versus Fuel: An Informed Introduction to Biofuels. London, UK: ZED Books, 2010:164-190.

3. Kline $\mathrm{KL}$, Msangi $\mathrm{S}$, Dale $\mathrm{VH}$, et al. Reconciling food security and bioenergy: Priorities for action. GCB Bioenergy 2016;9(3):557-576.

4. Berndes $G$, Ahlgren $S$, Börjesson $P$, et al. Bioenergy and land use change-State of the art. Wiley Interdisciplinary Reviews: Energy and Environment 2013;2(3): 282-303. 


\section{BIOFUELS, BIOENERGY, AND THE BIOECONOMY}

5. Scarlat N, Dallemand JF, Monforti-Ferrario, F, et al. The role of biomass and bioenergy in a future bioeconomy: Policies and facts. Environ Dev 2015;15:3-34

6. Piotrowski $\mathrm{S}$, Carus $M$, Essel R. Global bioeconomy in the conflict between biomass supply and demand. Ind Biotechnol 2015;11(6):308-315.

7. EU-COM. Renewable Energy Progress Report, 57 final. Report from the Commission to the European Parliament, the Council, the European

Economic and Social Committee and the Committee of the Regions, Brussels, Belgium: European Commission, 2017: 1-25.

8. Johnson FX, Silveira S. Pioneer countries in the transition to alternative transport fuels: Comparison of ethanol programmes and policies in Brazil, Malawi and Sweden. Environmental Innovation and Societal Transitions 2014;11:1-24
9. Souza GM, Victoria RL, Joly $C A$, et al. Bioenergy \& sustainability: Bridging the gaps. Paris, France: Scientific Committee on Problems of the Environment (SCOPE), 2015:5-7.

10. Liavoga A, Virgin I, Ecuru J, et al. Fostering a bio-economy in eastern Africa: Insights from Bio-Innovate. Nairobi, Kenya: International Livestock Research Institute (ILRI), 2016:12-97.

11. Bailis $R$, Drigo $R$, Ghilardi $A$, et al. The carbon footprint of traditional woodfuels. Nature Climate Change 2015;5(3):266-272.

12. Tilman D, Socolow R, Foley, JA, et al. Beneficial biofuels-The food, energy, and environment trilemma. Science 2009;325(5938):270-271. 